\title{
Alocação de alunos por turmas em rede municipal de ensino: percepções de diretores escolares
}

\author{
Allocating students in classes in the municipal school system: \\ perceptions of school's principals \\ Asignar estudiantes a clases en el sistema escolar municipal: \\ percepciones de los directores de las escuelas
}

\author{
Orcid Id: http://orcid.org/0000-0002-1267-8869
}

ANGELA MARIA MARTINS

Universidade Cidade de São Paulo

SANNY ROSA

Orcid Id: http://orcid.org/0000-0001-5044-6156

Universidade Municipal de São Caetano do Sul

SANDRA MARIA ZÁKIA LIAN SOUSA

Orcid Id: http://orcid.org/0000-0001-5171-8301

Universidade de São Paulo

\begin{abstract}
Resumo: Este artigo discute quais são os mecanismos de seleção adotados por diretores de escolas municipais para acolhimento e alocação de alunos por turmas e que podem, eventualmente, acentuar diferenças e desigualdades no processo de escolarização. Procedeu-se a uma dinâmica de grupo com a participação de 18 diretores de escolas e 5 assessoras da Secretaria de Educação Municipal de um município da Região Metropolitana de São Paulo. Os dados sinalizam as práticas que preponderam na rede municipal: matrícula por proximidade da rede física escolar; autoavaliações docentes; preferências docentes.
\end{abstract}

Palavras-chave: política educacional; diretores escolares; seleção de alunos; composição de turmas

\begin{abstract}
This article discusses the mechanisms of selection adopted by principals of municipal schools in order to receive and allocate students in classes and which may, eventually, accentuate differences and inequalities in the schooling process. A group dynamic was carried out with 18 school principals and 5 advisors from the Municipal Education Secretariat of a municipality in the Metropolitan Region of São Paulo. Data indicate that the practices that prevailed in the municipal network are: enrollment due to proximity to the school physical network; teacher self-assessments; and teaching preferences
\end{abstract}

Keywords: educational policy; school principals; selection of students; class composition 
Resumen: Este articulo analiza los mecanismos de selección adoptados por los directores de las escuelas municipales para recibir y asignar estudiantes a las clases y que, eventualmente, pueden acentuar las diferencias y las desigualdades en el proceso de escolarización. Se llevó a cabo una dinámica grupal con la participación de 18 directores de escuela y 5 asesores de la Secretaría Municipal de Educación de un municipio de la Región Metropolitana de la región de São Paulo. Los datos indican las prácticas que prevalecieron en la red municipal: inscripción debido a la proximidad a la red física de la escuela; autoevaluaciones de docentes; preferencias de enseñanza.

Palabras clave: politica educativa; directores de escuela; selección de estudiantes; composición de clase.

\section{INTRODUÇÃO}

Este artigo discute resultados da terceira etapa de uma investigação maior que apresentava como propósito a caracterização de cenários de gestão em escolas municipais e suas potencialidades de contribuir para a democratização da educação. A primeira etapa do estudo original tomou como fonte as respostas declaradas por 55.693 diretores municipais, de todas as redes municipais no Brasil, ao questionário contextual da Prova Brasil 2015 (REAL; SANTOS JUNIOR, SOUSA, MARTINS, BRAVO, 2019; MARTINS, SOUSA, MACHADO, REAL, BRAVO, 2018).

Ainda na primeira etapa da investigação - dentre outras dimensões de análise - discutiram-se os critérios para a composição da clientela nos estabelecimentos escolares e sua organização por turmas, com o objetivo de identificar possíveis implicações das práticas declaradas por todos os diretores das redes municipais de ensino ao questionário contextual da Prova Brasil, que pudessem incidir no processo de democratização da educação ${ }^{1}$. Frente às questões que emergiram nessa dimensão, especificamente, optou-se por realizar estudos de campo com diretores escolares de municípios localizados nos estados de São Paulo, Mato Grosso do Sul e Rio Grande do Sul, com o propósito de aprofundar a discussão e compreender quais mecanismos de seleção para acolhimento e alocação de alunos por turmas são adotados por eles e poderiam, eventualmente, acentuar diferenças e desigualdades no processo de escolarização e/ou estimular a concorrência entre escolas na busca por "melhores" alunos².

1 Na primeira etapa da investigação os resultados desse quesito foram publicados. Ver: Sousa, Martins, 2018.

2 Participaram da investigação maior os seguintes pesquisadores: Região Sul - Flávia Obino Werle; Alenis Andrade e Cristiane Welter (UNISINOS); Região Centro Oeste - Giselle Cristina Real, José Santos Silva Júnior (UFGD); Região Sudeste - Angela Maria Martins (FCC/UNICID), Sandra Zákia Sousa (FEUSP), Sanny Silva da Rosa (USCS), Maria Helena Bravo (FCC). A terceira etapa do estudo está disponível em: Martins, Real, Sousa, Rosa (2019). 
Neste artigo serão explorados os dados apenas de uma rede municipal de educação localizada na Região Metropolitana da Grande São Paulo (RMGSP). O campo teórico que fundamenta os resultados ora discutidos se ancora na perspectiva da sociologia da educação, conforme se discute adiante.

\section{APROXIMAÇÕES AO TEMA: APORTES DA LITERATURA}

No campo da Sociologia da Educação, inúmeros são os estudos que discutem os fatores condicionantes das desigualdades sociais e educacionais. Pesquisas como a de Coleman et al. (1966), realizada nos Estados Unidos, já apontavam a origem social das famílias, sexo, raça/cor, religião e localização das instituições de ensino como explicações para as desigualdades no desempenho escolar dos alunos, sugerindo que as escolas não fazem muita diferença.

No cenário internacional, as políticas públicas de educação implementadas a partir de fins dos anos de 1970 foram pautadas, gradativamente, por diretrizes ancoradas no princípio de igualdade de resultados, em substituição ao princípio de igualdade de oportunidades prevalecente até então. Em outros termos, essas diretrizes ampliaram as dimensões instrumentais do ensino em detrimento das dimensões culturais, com foco na noção de equidade, da tradição anglo-saxã de enfrentamento da pobreza. A igualdade de chances, constitutiva do Estado do Bem-Estar Social, pressupõe uma escola capaz de redistribuir riquezas e promover a mobilidade social; já a igualdade de resultados solicita da escola a seleção por mérito e a prestação de contas de sua eficácia para o Estado e para a sociedade. Nas palavras de Derouet, "O fim do século XX passou de uma definição da justiça centrada no objetivo de igualdade para uma concepção mais ampla que compreende tanto o reconhecimento das diferenças quanto a obrigação de prestar contas [...]" (2010, p. 1021).

O embate entre essas duas perspectivas levou à formulação de políticas educacionais, orientadas pela noção de equidade que levassem em conta as diferenças de circunstâncias e especificidades locais. As Políticas de Educação Prioritárias (PEPs) - assim denominadas genericamente - foram implementadas nos anos de 1970-1980, sucessivamente na Grã-Bretanha, na Suécia, na França e na Bélgica com o objetivo de reduzir desigualdades de escolarização e de sucesso escolar de alunos oriundos de segmentos menos favorecidos do ponto de vista econômico e social. Integrar os excluídos tornou-se uma preocupação no que se refere à justiça social, tornando o lugar das hierarquias, secundário.

Ancoradas em diretrizes compensatórias, essas políticas partem do princípio de que a igualdade de acesso é insuficiente para garantir a igualdade das oportunidades, havendo necessidade de reforço de ações e iniciativas 
governamentais e de unidades escolares para superar "déficits ou carências de ordem cultural, linguística ou intelectual que sofreriam os alunos impossibilitados de obter proveito da oferta escolar" (ROCHEX, 2011, p. 871). Na visão deste autor, as políticas compensatórias podem ser agrupadas em três opções governamentais: a escolha de segmentos populacionais, vítimas do fracasso e da desigualdade escolar que variam de minorias étnico-raciais, culturais ou linguísticas, dependendo do país; a seleção de territórios onde esses segmentos se concentram; e, finalmente, a escolha por "estabelecimentos escolares ou suas redes, considerados, ao mesmo tempo, como meio de atingir as populações escolares visadas e como escalão presumidamente eficaz para delimitar, elucidar e tratar as dificuldades e os problemas que levam às desigualdades [...]” (ROCHEX, 2011, 872).

Nesse contexto, emerge o debate sobre o "efeito-escola", assinalado por Van Haecht (2008), ao discutir pesquisa realizada entre 1983 a 1986 pelo Ministério da Educação da França, sobretudo, com a emergência de programas como as Zonas Geográficas Prioritárias (ZEP’s). De acordo com a autora, a primeira política educacional francesa de ação afirmativa foi implementada nos anos 1980 pelo então ministro Alain Savary, durante o governo do social-democrata François Mitterrand, a partir da configuração das Zonas Geográficas Prioritárias (ZEPs), localizadas em bairros "problemáticos" (geralmente periferias), nas quais as escolas e os próprios bairros poderiam se beneficiar de uma série de recursos adicionais para compensar suas situações de desvantagem relativa.

Ainda nessa direção, emerge a análise da eficácia escolar, baseada em três eixos: fatores escolares (lideranças fortes e democráticas; ambiente escolar favorável ao desenvolvimento de boas relações de trabalho e de aprendizagem; clima; recursos e materiais; trabalho em equipe); fatores da sala (qualidade das salas; relação professor-aluno; planejamento docente; metodologias e recursos didáticos; expectativas de sucesso escolar e avaliação permanente do progresso dos alunos); fatores associados ao pessoal docente (qualificação; formação continuada; condições de trabalho; estabilidade e experiência; relações professoraluno) (TORRECILLA, 2008, p. 479).

Estudos com esse enfoque emergiram com a finalidade de compreender a relação entre os processos escolares e o desempenho dos alunos, permitindo identificar os estabelecimentos escolares que, por conta de suas práticas pedagógicas, contrariavam as teses clássicas da Sociologia da Educação, obtendo resultados positivos com alunos oriundos de classes menos favorecidas social e economicamente. Em pesquisa realizada na rede municipal de Belo Horizonte, Alves, Soares (2007) explicam que o desempenho escolar varia em função dos critérios adotados pela escola para organizar os alunos por turmas. Segundo os 
autores "a diferença entre as turmas aumenta quando a escola agrupa alunos por nível de habilidade que, via de regra, coincide com o nível socioeconômico" (p. 40), o que contribui "para que pequenas diferenças entre os alunos se transformem em grandes diferenças entre os grupos e acirrem a estratificação escolar de uma forma mais ampla" (p.25).

Em trabalho que discute a noção de sucesso escolar, Perrenoud (2003) também chama atenção para o "processo de fabricação da excelência escolar", como uma dinâmica construída socialmente, em contextos complexos, nos quais coexistem os critérios adotados individualmente pelas instituições de ensino e aqueles definidos pelas avaliações padronizadas de larga escala. Por essa razão, o autor observa que:

[...] não se pode confundir os conhecimentos e as competências efetivas de uma criança e o julgamento de excelência escolar do qual ela é objeto [...], pois, o sucesso ou fracasso não são características intrínsecas dos alunos, mas o resultado de um julgamento feito pelos agentes do sistema educacional sobre a distância desses alunos em relação às normas de excelência escolar em vigor (p. 14).

O autor ressalta, ainda, que "o significado dos índices habituais de sucesso escolar dos alunos - taxas de promoção, notas, porcentagens - varia segundo o contexto". Por essa razão, assinala que notas iguais podem não corresponder

[...] às mesmas competências e competências iguais são avaliadas diferentemente de um estabelecimento e até de uma classe a outra, uma vez que as notas resultam em geral de uma comparação local entre alunos que seguem o mesmo programa. Assim um aluno médio pode parecer excelente numa classe muito fraca e medíocre numa classe muito forte (PERRENOUD, 2003, p. 11).

Tomando por base essas premissas, apresentam-se, a seguir, a metodologia e os procedimentos do estudo realizado no município de São Caetano do Sul que, por suas características sociais e educacionais, configura uma realidade especialmente propícia à discussão sobre a temática em tela neste artigo.

\section{METODOLOGIA DO ESTUDO}

Como se afirmou anteriormente, a investigação maior foi estruturada em etapas distintas e complementares. Na primeira etapa, foram processadas as respostas de 55.693 diretores de todas as escolas municipais no Brasil ao questionário contextual, por meio do software IBM SPSS Statistics - 20, gerando tabelas de contingência a partir dos registros agrupados em três dimensões de análise: a) trajetórias de formação e profissional; b) práticas de gestão declaradas por todos os diretores de escolas municipais no Brasil; c) condicionantes de funcionamento das 
redes escolares municipais. A segunda etapa teve como objetivo verificar possíveis relações entre características da trajetória de formação, acesso à função/cargo dos diretores, práticas de gestão declaradas e condições de funcionamento das escolas, e os resultados aferidos pelo Índice de Desenvolvimento da Educação Básica - Ideb. Realizou-se um tratamento estatístico por meio da aplicação da técnica Answer Tree da IBM SPSS Statistics - 20 (AT), para o qual foram selecionados 69 itens do questionário com maior potencial de discriminação das informações (BRAVO; MARTINS; SOUSA, 2019).

A partir dos dados da primeira e segunda etapas foram selecionadas as temáticas emergentes que apresentavam potencial de análise para a compreensão das práticas de diretores, com ênfase nas ações implementadas por diretores de escolas municipais, seus desafios e perspectivas, em torno dos seguintes temas: a) Conselho escolar; elaboração do PPP na escola; conselho de classe; b) formação continuada na escola, materiais didáticos e recursos pedagógicos utilizados; c) mediação de conflitos na escola e envolvimento com a comunidade escolar e entorno; d) critérios e estratégias para alocação de professores, para a matrícula de alunos e sua alocação por turmas; e) avaliações externas e estratégias para eventual organização pedagógica da escola, com base no uso de seus resultados.

Neste artigo serão explorados apenas os dados do estudo de campo, realizado na rede municipal de São Caetano do Sul. É preciso esclarecer que, embora a terceira etapa do estudo não tenha se configurado como pesquisa-ação - ou se ancorado no campo mais amplo da investigação-ação ${ }^{3}$ - optou-se por lançar mão do training group, sobretudo por considerarmos que a apresentação de problemas por um grupo de profissionais da educação e/ou de um diagnóstico inicial do modo como as escolas se organizam e funcionam podem constituir um dos elementos com potencial para reorientação de políticas públicas de educação.

$\mathrm{Na}$ visão de Lewin (1978), o planejamento de ações - a partir de diagnósticos - deve ser construído coletivamente pelos sujeitos envolvidos na pesquisa. Ressalta-se que o autor iniciou esse método na pesquisa-ação com formato de seminário, envolvendo trabalhadores sociais americanos denominados laboratórios sociais - definindo "um conjunto metodológico que buscava mudanças interpessoais, grupais e intergrupais a partir da análise da participação no laboratório e do relato das ocorrências na comunidade", com o objetivo de viabilizar soluções para problemas sociais por meio de intervenções (MELO; MAIA FILHO; CHAVES, 2016, p. 155).

3 Pesquisas referenciadas na investigação-ação - termo polissêmico - podem ser vistas a partir do campo mais amplo das teorias da ação e/ou da sociologia da ação. Ver: Guerra, 2010. 
De acordo com Melo, Maia Filho e Chaves (2016), o próprio Lewin ficou surpreso com o training-group frente ao interesse demonstrado por alunos que participaram de um laboratório, ao esclarecerem que gostariam de ser ouvidos, obtendo um feedback de suas colocações, expressões e sentimentos, possibilitando, dessa forma, a (re) formulação de caminhos possíveis para solução de problemas, o que originou o termo "dinâmica de grupo", cujo sentido - ancorado na física - significa movimento, vida, expressando "fenômenos subjetivos e psicológicos" (p. 155-156). Em suma, Kurt Lewin, precursor da pesquisa-ação, sugeria uma pesquisa que subsidiasse os grupos a promoverem mudanças, baseadas em reflexões sobre os problemas a serem enfrentados. Embora não considerasse as questões políticas e institucionais, - e, nessa direção, críticas contundentes foram dirigidas à concepção construída pelo autor ${ }^{4}$ - Lewin (1978) propôs dinâmicas de grupo que levariam a intervenções e, consequentemente, a possíveis mudanças na realidade dos indivíduos envolvidos nas situações estudadas.

De todo modo, as dinâmicas de grupo possibilitam processos de interação entre os sujeitos, influências recíprocas e ressignificação de noções e ideias. Ressalte-se que também constitui a essência dos fenômenos grupais - para além da interdependência - o objetivo de sua criação e a agregação dos sujeitos em torno de interesses comuns, que podem ser profissionais. Ademais, quando se trata de microgrupos, a limitação do espaço permite aos envolvidos - na interação face a face - percepções recíprocas uns dos outros, sem a interferência direta do pesquisador, ainda que este seja o mediador da situação (LUFT, 1970).

Vale ressaltar, ainda, que a participação de profissionais e/ou atoreschaves das situações estudadas em dinâmicas de grupo, painéis de discussão e demais modalidades de reunião - como os grupos focais e grupos operativos possibilita a emergência de expressões, sentimentos e informações [...] "que podem ser vistas, ouvidas ou sentidas diretamente pelo pesquisador” (STAKE, 2011, p. 103). Esses procedimentos permitem desvelar significados atribuídos pelos atores envolvidos na investigação, e que podem, inclusive, mudar seu percurso, tendo em vista o processo interativo estabelecido entre pesquisador e pesquisados, complexificando o problema proposto inicialmente. De acordo, ainda, com Stake (2011, p. 103), “a interpretação [...] continua a reformular o estudo durante sua realização" [...], sobretudo se considerarmos que o pesquisador pode utilizar "sua habilidade intuitiva de enxergar os detalhes, de reconhecer a influência do contexto [...], de focar progressivamente" (p. 104). Embora, instrumentos fechados sejam

4 Sobre as críticas feitas às dinâmicas de grupo - enquanto constructo teórico e técnica de pesquisa assim como às teorias que ancoram estudos com microgrupos, ver: Melo; Maia Filho; Chaves, 2014. 
relevantes para não se perder de vista a questão central e facilitar "a agregação dos dados", o olhar, a sensibilidade e o conhecimento do pesquisador são fundamentais para capturar singularidades dos fatos estudados.

Acrescente-se também que o estudo procedeu à exploração de fontes documentais da política educacional, implementada no município de São Caetano do Sul, em interlocução com estudos relacionados ao tema e os dados coletados em campo, compondo a triangulação, procedimento necessário para ampliar a fidedignidade dos achados e esgotar a possibilidade de exploração do objetivo do estudo.

Nessa perspectiva, os conteúdos foram tratados em dinâmica de grupo com um grupo de 18 diretores municipais (de um total de 20 diretores) da rede municipal de São Caetano do Sul, e 5 assessoras de formação do Centro de Capacitação de Profissionais da Educação Dra. Zilda Arns (CECAPE) - órgão ligado à Secretaria Municipal de Educação ${ }^{5}$. Esse grupo de diretores e assessoras de formação era composto por quatro homens e dezoito mulheres ${ }^{6}$, com idades entre 30 e 60 anos: 31-40 (2); 36-40 (2); $41-45$ (5); 46-50 (7); $51-55$ (3); 56-60 (2); NR (2); ou seja, a maioria encontra-se na faixa etária entre 40 a 50 anos.

Inicialmente, houve o registro de respostas individuais, obedecendo a um roteiro semiestruturado. Finalizados os registros individuais, destinou-se um tempo maior para as discussões em grupo, com o intuito de trocar, complementar e aprofundar os registros individuais. Com esse fim, foram formados seis subgrupos, que elegeram um relator para apresentar e representar cada um deles no painel geral de discussões. Durante a exposição dos relatores, emergiram as questões, os conflitos, os interesses comuns e consensos, as divergências de opiniões, os desafios, os pontos de atenção e as sugestões para a Seduc de São Caetano do Sul.

O conteúdo de cada tópico das discussões foi sistematizado e registrado em slides projetados simultaneamente em telão para que os diretores se reconhecessem nas respostas e nos problemas apresentados pelos relatores. Da mesma forma, e com intenção de serem ouvidos não apenas pelos pesquisadores, mas pelos órgãos centrais, foram registrados e discutidos possíveis encaminhamentos para

5 A atividade foi realizada em parceria com a Secretaria Municipal de Educação de São Caetano do Sul, que autorizou e convocou os diretores para participarem da pesquisa, e com a Universidade Municipal de São Caetano do Sul (USCS), que cedeu salas de aula e recursos didáticos para a realização das atividades. Antes do início da coleta do material, houve o esclarecimento dos termos de realização da pesquisa, tendo-se obtido o consentimento dos participantes de forma expressa.

6 Um dos diretores não respondeu a ficha individual, daí os dados referirem-se a 22 e não 23 participantes. 
subsidiar políticas públicas de educação no âmbito municipal. Os resultados obtidos na dinâmica de grupo foram, posteriormente, discutidos e sistematizados pelos pesquisadores.

Neste texto, serão explorados apenas os dados que se referem aos mecanismos de seleção para acolhimento e alocação de alunos por turmas, adotados por eles, e que poderiam, eventualmente, acentuar diferenças e desigualdades no processo de escolarização e/ou estimular a concorrência entre escolas na busca por "melhores" alunos. A partir das discussões em subgrupos, os (as) participantes escolheram um relator para apresentar a síntese das falas em um painel geral organizado para trocas de ideias e experiências, com o propósito de registrar, principalmente, as ações implementadas em suas unidades escolares, os desafios e perspectivas de trabalho.

\section{LÓCUS DO ESTUDO}

A cidade de São Caetano do Sul é um pequeno município brasileiro, situado na região do grande $\mathrm{ABC}$ Paulista (limites com as cidades de São Paulo, Santo André e São Bernardo do Campo). Com uma economia ligada incialmente às indústrias, nas últimas décadas São Caetano do Sul vem mudando o seu perfil econômico para o setor de serviços, em grande parte, por consequência da migração das grandes indústrias automobilísticas da região para cidades do interior ou para outros estados 7 . O município apresenta bons indicadores educacionais: em 2010, na faixa etária compreendida entre 18 e 24 anos, 75,53\% possuíam o ensino médio completo, sendo que a taxa de analfabetismo da população com 15 anos ou mais era de apenas $1,55 \%$.

A rede municipal de São Caetano, até 2017 subordinada à Diretoria Regional de Ensino da Região de São Bernardo do Campo - órgão da Secretaria de Estado da Educação de São Paulo -, tornou-se Sistema Municipal de Ensino por meio da aprovação da Lei $\mathrm{N}^{0}$ 5.556, de 20 de setembro de 2017, que dispõe sobre sua criação e fixa normas para o funcionamento de seus órgãos, com vistas à garantia do direito à educação e cumprimento das metas do Plano Municipal de Educação. O Sistema compreende os órgãos municipais (Secretaria Municipal de Educação e Conselho Municipal de Educação) e as instituições educacionais (rede escolar de Educação Básica, mantida pelo Poder Público Municipal e instituições de educação infantil, criadas e mantidas pela iniciativa privada).

\footnotetext{
7 Conforme reportagem do Jornal Valor Econômico de 26/03/2019, com base em estudo da Universidade Municipal de São Caetano do Sul (USCS), o PIB industrial das sete cidades que compõem a região do ABC sofreu retração de "quase 39\%, muito acima das quedas registradas no Brasil (11,5\%) e no Estado de São Paulo (14,73\%)”. Disponível em: https://valor.globo.com/empresas/coluna/abc-encolhe-e-pode-virarregiao-simbolo-da-desindustrializacao-no-pais.ghtml. Acesso em agosto de 2019.
} 


\section{Quadro 01 - Dados da rede municipal de São Caetano do Sul}

\begin{tabular}{|l|l|}
\hline IDEB - Anos iniciais do ensino fundamental [2015] & 7,2 \\
\hline IDEB - Anos finais do ensino fundamental [2015] & 6,0 \\
\hline IDEB - Anos iniciais do ensino fundamental [2017] & 7,5 \\
\hline IDEB - Anos finais do ensino fundamental [2017] & 6,4 \\
\hline Matrículas na educação infantil [2017] & 5.544 matrículas \\
\hline Matrículas no ensino fundamental [2017] & 11.873 matrículas \\
\hline Matrículas no ensino médio [2017] & 1.540 matrículas \\
\hline Matrículas na EJA [2017] & 364 matrículas \\
\hline Matrículas na educação especial [2017] & 590 matrículas \\
\hline Docentes na educação infantil [2017] & 367 docentes \\
\hline Docentes no ensino fundamental [2017] & 748 docentes \\
\hline Docentes no ensino médio [2017] & 107 docentes \\
\hline Número de estabelecimentos de educação infantil [2017] & 40 escolas \\
\hline Número de estabelecimentos de ensino fundamental [2017] & 21 escolas \\
\hline Número de estabelecimentos de ensino médio [2017] & 3 escolas \\
\hline
\end{tabular}

Fonte: Censo Escolar/INEP 2017

De acordo com o Plano Municipal de Educação de 2015-2025 - aprovado pela Lei n. 5.316/2015 -, a educação municipal de São Caetano do Sul recebe investimentos superiores a $25 \%$ da arrecadação total do município e possui, em sua estrutura, todas as crianças da educação infantil matriculadas na rede municipal de ensino. O Plano Municipal de Educação da cidade de São Caetano do Sul afirma, ainda, que a política educacional do município foi construída de forma coletiva e por meio de responsabilidade compartilhada, buscando responder às demandas da rede.

O documento registra um conjunto de ações que busca integrar diferentes esferas administrativas e profissionais do município, além de instâncias da sociedade civil: Secretaria Municipal de Educação; Conselho Municipal de Educação; Comissão de Educação da Câmara dos Vereadores; Secretaria Municipal de Finanças; Secretaria Municipal de Administração; Sindicatos de trabalhadores da educação; Associações comerciais, industriais e agrícolas; Diretores de escolas municipais, estaduais e privadas, Pais e estudantes das escolas; Gestores de Institutos Federais de Educação, Ciência e Tecnologia; Gestores de Universidades Estaduais e Federais; Proprietários e trabalhadores em meios de comunicação; Religiosos de Igrejas majoritárias no município; Movimentos sociais, associações de bairro.

O texto do PME, articulado ao Plano Nacional de Educação (PNE), está estruturado em 20 metas (cada uma com suas respectivas estratégias) e apresenta ações no sentido de: erradicar o analfabetismo, universalizar o atendimento 
escolar; superar as desigualdades educacionais; melhorar a qualidade da educação; formar para o trabalho e para a cidadania; promover o princípio da gestão democrática da educação pública; promover as questões humanística, científica, cultural e tecnológica do país; estabelecer metas de aplicação de recursos públicos em educação; valorizar os profissionais da educação; promover os princípios do respeito aos direitos humanos, à diversidade e à sustentabilidade socioambiental (SÃO CAETANO DO SUL, 2015, p. 47).

\section{DISCUSSÃO DOS RESULTADOS}

Na primeira etapa da investigação, as questões 37 a 39 do questionário dos diretores da PB 2015 exploraram a disponibilidade de vagas na escola e os processos de acolhimento e de alocação dos alunos por turmas, adotados pelos diretores. Especificamente a questão 37 tratava sobre a composição da clientela escolar, ao perguntar qual teria sido o critério para a admissão de alunos pela escola. Dentre as alternativas, constavam as seguintes formas: a) Prova de seleção; b) Sorteio; c) Local de moradia; d) Prioridade por ordem de chegada; e) outro critério. Verificou-se que o processo seletivo foi assinalado por 1,2\% dos diretores de EFI e por 1,3\% dos diretores de EFII, indicando que a aplicação de provas para selecionar "os mais aptos ou preparados é um procedimento raramente adotado nas escolas de ensino fundamental" (MARTINS et ali, 2018). No município estudado, conforme fonte oficial (SÃO CAETANO DO SUL, 2017b), este critério é adotado apenas nas escolas que oferecem o ensino médio, e com um alto grau de exigência.

No cenário de gestão de escolas municipais no Brasil, a alternativa de sorteio, que revela que a escola não realiza qualquer influência para seleção dos ingressantes, foi a opção indicada por $0,4 \%$ do total de diretores de EFI e EFII; no município estudado, esse critério é adotado somente nas 7 (sete) escolas de tempo integral do município de um total de 20 escolas de EF I e II, número alto considerando-se que se trata de uma rede de ensino pequena (SÃO CAETANO DO SUL, 2017b).

Nas demais escolas, o critério de alocação de vagas é o local de moradia, o qual correspondia à alternativa D do questionário da PB 2015. A prática de matrícula setorizada foi indicada por $42,8 \%$ dos diretores de EFI e por $39,9 \%$ dos diretores de EFII pesquisados na primeira fase da pesquisa, o que indica uma tendência de utilização, por parte dos sistemas públicos, do critério de proximidade do local de moradia dos alunos. 
Contudo, nas escolas públicas do estado de São Paulo, as regras e procedimentos de matrícula são definidos em regime de colaboração entre a Secretaria da Educação do Estado de São Paulo e as secretarias municipais de educação. Recentemente, com o objetivo de atender plenamente à demanda do ensino fundamental, a Resolução SE nº 45, de 18 de julho de 2018 definiu critérios e procedimentos para a implementação do Programa Matrícula Antecipada/ Chamada de alunos, estabelecendo que:

Artigo $2^{\circ}$ - Todas as etapas do processo de matrícula antecipada para o Ensino Fundamental serão realizadas pela rede estadual e pelas redes municipais de ensino, em conjunto e articuladamente, por meio da plataforma "Secretaria Escolar Digital" - SED, na conformidade do que estabelece a Resolução SE $n^{\circ}$ $36 / 2016$.

Assim, a proximidade entre a escola e a residência do aluno permanece como critério principal de preenchimento das vagas nesse sistema, haja vista a exigência de preenchimento de dados que possibilitem a geolocalização dos candidatos inscritos. Contudo, a Resolução SE 45/2018 faculta a indicação da escola "por interesse do próprio aluno, ou de seus pais/responsáveis, não sendo necessário haver mudança de endereço para se efetivar a inscrição na escola pretendida (...)", o que poderá ocorrer, desde que haja vaga na unidade de preferência.

Essa medida oficial sinaliza a abertura das redes escolares públicas no estado de São Paulo ao princípio da livre escolha da escola pela família (school choice), o que remete a uma discussão sobre a competição por vagas em escolas públicas com reputação de "boa qualidade". Estudiosos sobre esse tema chamam a atenção para o "efeito da composição socioeconômica dos alunos e de uma possível seleção social, operado no nível dos estabelecimentos escolares” (COSTA, KOSLINSKI, 2011, p. 250).

As falas dos diretores indicam que as escolas identificam perfil e número de alunos por turma, aqueles que necessitam de atenção especial, assim como a distribuição por gênero. Contudo, conforme sinaliza a fala de um dos diretores, os critérios de matrícula por proximidade da rede física escolar, são operados de forma centralizada pela Secretaria Municipal de Educação:

Com relação às matrículas de alunos na escola e sua alocação por turmas, os professores observam o perfil do aluno; o número de alunos por turma; o número de alunos de inclusão; e o número de meninos e meninas. (Sujeito 8)

Com relação à matrícula dos alunos, elas já vêm determinadas pela Seduc, sem grandes possibilidades de alteração. (Sujeito 10) 
É possível inferir, entretanto, que a utilização desses critérios pode não impedir a prática de outros mecanismos de seleção e/ou rejeição de alunos considerados problemáticos, seja por questão de desempenho ou por situações de indisciplina e/ou violência (ALVES et al., 2015). Por ser um município pequeno, as escolas dessa rede municipal de ensino tendem a reunir alunos com perfil socioeconômico e cultural semelhante, o que pode conferir certa homogeneidade à composição do corpo discente nas escolas.

Nessa direção, fontes indicam que os munícipes convivem com uma atmosfera de intensa competitividade na busca por vagas nas escolas consideradas de melhor qualidade, tendo em vista a grande densidade demográfica da cidade (9.865 habitantes por km2), de acordo com a Fundação SEADE (2020). Acrescentese ainda que, a despeito dos elevados indicadores sociais antes mencionados, 6,42\% dos domicílios particulares possuíam renda familiar até de até $1 / 2$ salário mínimo, e 2,83\% até $1 / 4$ do salário mínimo, segundo Censo Demográfico de 2010 (IBGE, 2010).

Das 20 escolas municipais de ensino fundamental, 10 são escolas de período integral, as quais contam com infraestrutura física e material diferenciada, como quadras poliesportivas, laboratórios, inclusive de informática, espaços para atividades culturais, bibliotecas, auditórios, cozinhas, refeitórios, banheiros, entre outros equipamentos (SÃO CAETANO DO SUL, 2015). Essas escolas são alvo de grande disputa, razão pela qual a Secretaria de Educação abre inscrições anualmente para o preenchimento de vagas no ensino fundamental em escolas de período integral. Os critérios são os que seguem:

O aluno deverá possuir 6 (seis) anos completos ou que venha a completar até o dia 30/06/2018; residir no município de São Caetano do Sul e a mãe ou responsável legal exercer atividade remunerada, fora do lar, por período igual ou superior a 06 (seis) horas diárias e no mínimo 03 dias por semana (SÃO CAETANO DO SUL 2017a, p. 2).

As vagas de $1^{\circ}$ ano do ensino fundamental em escolas de período integral são preenchidas por sorteio público, cujo resultado é acompanhado pelo número contido no protocolo de inscrição, previamente realizada pelo responsável pelo aluno, junto ao CECAPE, em data definida no Edital. As vagas são preenchidas na ordem de contemplação do aluno no ato do sorteio, obedecendo às opções de preferência indicadas pelo responsável pelo aluno e considerando a disponibilidade de vagas em cada escola. Algumas vagas são previamente reservadas para contemplar a Lei da Irmandade - Lei Municipal n. 
5.139/13 (SCS, 2013), que dispõe sobre a obrigatoriedade da matrícula de irmãos no mesmo estabelecimento de ensino quando este oferecer turmas no mesmo nível educacional (SÃO CAETANO DO SUL, 2013).

Embora a Prefeitura de SCS declare grande empenho em garantir vagas a todos os inscritos para o $1^{\circ}$ ano do Ensino Fundamental nas EMEFs de período integral, o próprio uso do dispositivo de sorteio indica a existência de uma distância entre a demanda por esse tipo de escola e a capacidade de oferta de vagas pelo município. (SÃO CAETANO DO SUL, 2017a)

Já o acesso às vagas do Ensino Médio nas escolas municipais se dá por meio de processo seletivo classificatório dos ingressantes no primeiro ano da última etapa da educação básica, indicando a captação dos alunos com melhor desempenho acadêmico, visto que os candidatos remanescentes têm a opção de matrícula nas dez escolas estaduais localizadas no município. O processo seletivo de ingresso ao EM nas escolas municipais de SCS se dá por meio de provas, compostas por 15 questões cada uma, nas áreas de Português, Matemática e Conhecimentos Gerais. Além disso, o aluno também se submete a uma prova de Inglês Básico, composta por 5 questões. Os conhecimentos contemplados nas provas expressam o alto padrão de exigência requerido dos candidatos, com ênfase em Português e Matemática, incomum em grande parte das escolas brasileiras (SÃO CAETANO DO SUL, 2017b).

Esse tipo de prática, comum em países que visam impulsionar a liberdade de escolha da escola pelas famílias, é rara nos sistemas públicos brasileiros. Daí que, ao invés de associá-la ao conceito de "quase-mercado" (LE GRAND, 1991), pesquisadores brasileiros (COSTA; KOSLINSKI, 2011; 2012) têm operado com a noção de "quase-mercado oculto", pois, no Brasil, inexistem políticas claras e regulamentadas com esse objetivo. Por isso, os autores entendem que:

[...] em nosso caso, a quase ausência de regras para a disputa por vagas nas escolas que atendem à imensa maioria da população promove a desigualdade de oportunidades escolares de forma mais severa que a observada em contextos criticados pelos opositores de políticas de school-choice. Enfim, o processo parece acentuar características promotoras de desigualdade social, ampliando as chances de quem já desfruta de alguma vantagem competitiva, frequentemente associada ao patrimônio de relações sociais (COSTA; KOLINSKI, 2012, p. 197).

No que se refere aos critérios para agrupamento dos alunos, o Regimento Escolar, definido pela Seduc para todas as escolas da rede municipal de SCS, estabelece que: 
Art. 58- As classes serão organizadas de acordo com o ano cursado pelos alunos, adotando-se como regra o agrupamento heterogêneo;

Art. 60 - Poderão ser organizadas classes que reúnam alunos de diferentes anos e equivalentes níveis de adiantamento, para as atividades.

$\mathrm{Na}$ dinâmica realizada com os diretores procurou-se apreender as estratégias efetivamente utilizadas para seguir essa regra regimental, assim como os desafios e perspectivas apontados para melhorar a organização escolar. Algumas práticas aparentemente consensuais foram apontadas no painel geral em relação a esse eixo temático. De acordo com os participantes da pesquisa,

As salas são organizadas considerando diferenças (raciais, gênero, dificuldades etc.) já observadas pelo grupo de professores anteriormente, pensando no melhor aproveitamento dos alunos. Composição heterogênea [das turmas], com atenção voltada à equalização da quantidade de alunos com dificuldades/deficiências em cada sala), considerando critérios disciplinares. (Registros do Painel Geral, grifos nossos).

Tanto nas discussões em grupo, como no painel geral, as informações fornecidas pelos diretores não foram suficientes para esclarecer os critérios efetivamente utilizados para a alocação dos alunos nas turmas. As falas e registros contém elementos vagos que dão margem a diferentes interpretações. A declaração de que os professores "consideram as diferenças" pensando "no melhor aproveitamento dos alunos", por exemplo, é altamente subjetiva e ambígua, podendo tanto sugerir o entendimento de que o aproveitamento dos alunos será melhor quanto maior a heterogeneidade da classe, como o contrário. Não se pode deixar de notar também que o cuidado com a "equalização" das diferenças e com a distribuição quantitativa dos alunos "com dificuldades/deficiências" entre as salas pode ser uma estratégia negociada no âmbito das escolas - com base no que chamaram de "critérios disciplinares" - para buscar alguma homogeneidade sem quebrar o princípio da heterogeneidade previsto no Regimento.

Assim, as estratégias de fala e as lacunas discursivas dos diretores durante a dinâmica de grupo reforçam considerações realizadas sobre os resultados da primeira etapa, conforme apontam Sousa, Martins (2018):

As alternativas que se referem à organização de classes homogêneas - agrupar alunos da mesma idade ou agrupar alunos com rendimento similar - tanto podem apontar para uma direção de não separação de alunos em razão de seu nível de desempenho escolar, quanto podem indicar a adoção de estratégia de segmentação, que tende a induzir a processos discriminatórios e seletivos no interior da escola. (p. 183). 
Os critérios adotados para alocação de professores por classes ou turmas foram investigados na questão 40 do questionário da PB de 2015, na primeira etapa da investigação. Embora não excludentes, foi solicitado que o respondente assinalasse apenas uma dentre as seguintes alternativas oferecidas no questionário: a) Preferência dos professores; b) Escolha dos professores, de acordo com a pontuação por tempo de serviço e formação; c) Professores experientes com turmas de aprendizagem mais rápida; d) Professores experientes com turmas de aprendizagem mais lenta; e) Manutenção do professor com a mesma turma; f) Revezamento dos professores entre as séries; g) Sorteio das turmas entre os professores; h) Atribuição pela direção da escola; i) Outro critério; j) Não houve critério.

Verificou-se, na primeira etapa, que a distribuição das respostas dos diretores apresentou maiores concentrações na alternativa B (Escolha dos professores, de acordo com a pontuação por tempo de serviço e formação), assinalada por $23,8 \%$ dos diretores de EFI e $23,3 \%$ dos diretores de EFII; na alternativa $\mathrm{H}$ (Atribuição pela direção da escola), assinalada por 16,1\% dos diretores de EFI e 14,4\% dos diretores de EFII e na alternativa A (Preferência dos professores), apontada por 14,6\% dos diretores de EFI e 11,1\% dos diretores de EFII. Considera-se, então, que 54,6\% dos diretores de EFI e 48,9\% dos diretores de EFII, ao procederem à atribuição de turmas/aulas entre os professores de suas escolas, tendem a não utilizar um critério de decisão pedagógica, que permita discutir sua possível adequação para o enfrentamento das questões de desigualdades intraescolares e de dificuldades de aprendizagem dos alunos (MARTINS et ali, 2018).

$\mathrm{Na}$ dinâmica de grupo, a questão foi colocada em pauta com os diretores, mas sem apresentação de alternativas que induzissem a qualquer tipo de resposta, tendo em vista que o propósito da atividade com o grupo de diretores era possibilitar a livre expressão dos participantes. Verificou-se que a prática mais comum às escolas dessa rede são as "autoavaliações", realizadas pelos docentes com a finalidade de alocar os professores nas turmas. Com base nessa autoavaliação, segundo os diretores, é possível fazer uma "análise sobre a interação do professor com seu grupo de trabalho e sua atuação com os alunos". Também aparece como consensual e desejável a postura de "Manter a escolha mais democrática possível para a preferência dos professores" (Registros do painel geral de discussões, grifo nosso).

Observou-se que a adoção do critério "Preferência dos professores" (correspondente à alternativa A do questionário PB 2015) é o procedimento mais comum de atribuição de turmas/aulas entre os professores nas escolas de SCS. Com base na análise do questionário, cotejada com o que diz a literatura sobre o 
tema, considerou-se, na primeira fase da investigação, que esse procedimento assim como as alternativas B (Escolha dos professores, de acordo com a pontuação por tempo de serviço e formação) e H (Atribuição pela direção da escola) - não trazem subjacente um critério de decisão, que permita uma apreciação deste quanto à sua desejabilidade.

Além disso, o entendimento de que respeitar a "preferência" dos professores por determinadas turmas corresponde a manter práticas "democráticas" é bastante controverso. Isso porque certas escolhas podem ser, em alguns casos, orientadas por estereótipos que levam à discriminação dos alunos, como também podem reforçar um entendimento comum sobre o que venha a ser a "melhor sala" ou a "classe ideal". Levar em conta motivações pessoais e critérios subjetivos subjacentes às "preferências" dos professores pode, ainda, aprofundar desigualdades já existentes na escola, ao invés de minimizá-las. Sobre esses critérios, os seguintes comentários foram extraídos dos registros individuais de dois sujeitos:

Para a alocação de professores e atribuição das turmas, consideramos o perfil do professor; uma autoavaliação preenchida por ele; a análise do desempenho com a turma no ano anterior; e há casos pré-determinados pela Seduc. (Sujeito 8, grifos nossos).

Para a alocação de professores e atribuição das turmas são considerados o perfil do professor, as demandas da escola e os anseios de turmas, entre outros. (Sujeito 10).

Praticada, ao que parece, em todas as escolas, chama a atenção a declaração do Sujeito 8 de que a autoavaliação é "preenchida" pelo professor, pois pode-se inferir que se trata de um instrumento estruturado e padronizado, cuja autoria pode ser tanto da direção da escola como de órgãos centrais da rede, procedimento que reduziria possibilidades de reflexões pessoais dos docentes.

\section{CONSIDERAÇÕES}

As falas e expressões dos diretores participantes da dinâmica de grupo permitem afirmar que os parâmetros utilizados no instrumento de auto avaliação do professor se pautam pelas prioridades da Secretaria de Educação, cujo foco mais evidente é o desempenho escolar dos alunos, particularmente nas avaliações externas, o que indica uma característica centralizadora na gestão da rede de ensino, já comentada por outros estudos (ROSA, CAMPOS, PADOVAN, UMEMURA, 2018). 
Nessa direção, é possível compreender por que a análise do "desempenho com a turma no ano anterior" aparece como o segundo critério apontado no primeiro depoimento. A informação adicional, fornecida pelo mesmo sujeito, de que "há casos" em que alocação de professores é "pré-determinada pela Seduc" reforça o raciocínio de que há um controle sobre o processo de auto avaliação dos docentes por meio de instrumento fechado a ser preenchido, em direção contrária às concepções preconizadas por diversas diretrizes oficias, e debatidas em inúmeros estudos da área que apresentam críticas e/ou propõem subsídios para o aprimoramento das práticas avaliativas na educação. (ASSIS, AMARAL, 2013; FREITAS, 2012; BRASIL, 2012; AÇÃO EDUCATIVA, UNICEF, PNUD, INEP-MEC, 2004). Vale destacar, ainda, o processo de autoavaliação institucional - denominado Avaliação Institucional Participativa - implementado em rede municipal de ensino no interior do estado de São Paulo, com vistas a favorecer a atuação dos coletivos escolares. (SORDI et al, 2012).

Chama atenção também que o "perfil do professor", mencionado pelos dois diretores, seja um dos critérios para atribuição das turmas entre os docentes. Infelizmente, não foi possível explorar os atributos considerados na avaliação desse "perfil" e, tampouco, em que sentido e com quais preocupações tais atributos se convertem em fator relevante para a organização das turmas. Contudo, fica nítido que as "demandas da escola" - cujo teor também não foi suficientemente esclarecido - preponderam, "entre outros" critérios, para essa organização. Vale registro de que o "anseio dos estudantes" foi mencionado por um dos diretores como elemento a ser considerado na designação da classe ao professor, embora não se possa afirmar que esse critério figure entre os que têm maior peso e importância, dadas as características de gestão e as prioridades das políticas educacionais da rede de São Caetano do Sul.

Um ponto comum entre os três tópicos analisados neste eixo temático (critérios e estratégias de matrículas, de alocação de alunos por turma e distribuição das turmas pelos docentes) é a preocupação com a não seletividade e não discriminação dos alunos por critérios de desempenho acadêmico e/ ou comportamentais, fatores sobejamente estudados como responsáveis pelo aprofundamento das desigualdades socioeconômicas e culturais dos estudantes de escolas públicas brasileiras. Sem dúvida, a polêmica entre heterogeneidade $\mathrm{x}$ homogeneidade é a que, em última instância, se coloca no cerne das decisões dos gestores acerca da melhor forma de organização escolar.

Em suma, os dados corroboram outros estudos sobre a complexidade que envolve a composição de turmas homogêneas. Na primeira etapa da investigação maior, citada anteriormente, há a sinalização de que não é possível identificar a "opção por constituição de classes homogêneas ou heterogêneas", 
isto é, qual estratégia prepondera nas redes de ensino municipais no Brasil (SOUSA, MARTINS, 2018). As autoras concluem que, embora em percentual pequeno, diretores declararam ao questionário contextual que organizam classes homogêneas de acordo com o rendimento escolar, "o que revela uma prática que tende a intensificar desigualdades” (p. 188). Em outra pesquisa, realizada em Belo Horizonte, conclui-se que não se trata de apoiar a ideia de "turmas homogêneas ou heterogêneas", porém, trata-se de compreender que a "seletividade e a discriminação" prejudicam os alunos que apresentam dificuldades de aprendizagem, pois para estes, devem ser elaboradas estratégias específicas que subsidiem a superação dessas dificuldades (BARBOZA, 2006, p. 106).

A análise dos registros de diretores de escolas de ensino fundamental do município de São Caetano do Sul aponta para a existência velada de uma tensão entre essas duas possibilidades, um problema que, ao fim e ao cabo, pode bem ser colocado como uma falsa questão.

Contudo, é preciso ressaltar que a reunião de grupos de interesse - tal como a dinâmica de grupo realizada com os diretores escolares do município para discutir situações julgadas por eles como conhecidas (inseridas em zona de conforto), configura um campo de tensão e de desafios que promove, muitas vezes, "um exercício mais difícil do que" [os profissionais poderiam] "supor e, em todo o caso, um exercício por vezes incômodo" (LIMA, 1996, p. 1). Nessa direção, identificou-se por meio da interação com os (as) diretores (as) na atividade realizada, que pode ser mais confortável reproduzir discursos oficiais e/ou dissimular o esclarecimento sobre quais ações ou estratégias implementam em suas unidades para seleção, acolhimento e alocação de alunos por turmas, do que propriamente desvelar as dificuldades, tensões e limites da gestão escolar, em contexto de política educacional centralizadora, o que parece ocorrer no município estudado.

\section{REFERÊNCIAS}

AÇÃO EDUCATIVA, UNICEF, PNUD, INEP-MEC (coordenadores). Indicadores da qualidade na educação, São Paulo: Ação Educativa, 2004. Disponível em: http://portal.mec.gov.br/seb/arquivos/pdf/Consescol/ce_ indqua.pdf. Acesso em 12/05/2019.

ALVES, M. T. G.; SOARES, J. F. Efeito-escola e estratificação escolar: o impacto da composição de turmas por nível de habilidade dos alunos. Educação em Revista, Belo Horizonte, n. 45, June 2007, p. 25-59, 
ASSIS, L. M. de; AMARAL, N. C. Avaliação da educação - por um sistema nacional. Revista Retratos da Escola, Brasília, v. 7, n. 12, p. 27-48, jan. /jun. 2013.

BRASIL. Ministério da Educação. Educação infantil: subsídios para construção de uma sistemática de avaliação. Brasília, DF: MEC, 2012. (Documento produzido pelo Grupo de Trabalho instituído pela Portaria no 1.147/2011, do Ministério da Educação). Disponível:http://portal.mec.gov.br/index.php?option=com_cont ent\&view $=$ article\&id $=12579 \% 3$ Aeducacao-infantil\&Itemid $=859>$. Acesso em: 21 maio 2013.

BRAVO, M. H.; MARTINS, A. M.; SOUSA, S. Z. Cenários de gestão de escolas municipais da região sudeste e o IDEB: possíveis associações. Anais do XXIX Simpósio Brasileiro de Política e Administração da Educação, 2019, p. 18689.

COSTA, M. da; KOSLINSKI, M. Quase mercado oculto: disputa por escolas "comuns" no Rio de Janeiro. Cadernos de Pesquisa, São Paulo, v. 41, n. 142, p. 246-266, jan./abr. 2011.

COSTA, M. da; KOSLINSKI, M. Escolha, estratégia e competição por escolas públicas. Pro-Posições, Campinas, v. 23, n. 2, p. 195-213, maio/ago. 2012.

DEROUET, J-L. Crise do projeto de democratização da educação e da formação ou crise de um modelo de democratização? Algumas reflexões a partir do caso francês (1980-2010). Educação e Sociedade, Campinas, v. 31, n. 112, Sept. 2010. p. 1001-1027

FREITAS, L. C. de. Qualidade negociada: avaliação e contra-regulação na escola pública. Educação e Sociedade, Campinas, v. 26, n. 92, p. 911-933, out. 2005.

FUNDAÇÃO SEADE. Perfil dos Municípios Paulistas, São Caetano do Sul. Disponível em: https://perfil.seade.gov.br Acesso em: 22 jul. 2020.

HAECHT, A. Van. Sociologia da Educação - a Escola Posta à Prova. Artmed, Porto Alegre, 2008.

LE GRAND, J. Quasi-Markets and Social Policy. The Economic Journal, v. 101, n. 408, p. 1256-1267, set. 1991. 
LEWIN, Kurt. Problemas de dinâmica de grupo. São Paulo: Cultrix, 1978.

LIMA, L. C. Construindo modelos de gestão escolar. Lisboa: Instituto de Inovação Educacional, 1996.

LUFT, J. Introdução à dinámica de grupo. Lisboa: Moraes, 1970.

MARTINS, A. M.; SOUSA, S. ZÁKIA, L.; MACHADO, C.; REAL, G. C.; BRAVO, M. H. Cenários de gestão de escolas municipais: questionário contextual da Prova Brasil. Cadernos de Pesquisa. São Paulo, v. 48, n. 170, 2018, p. 10381061.

MARTINS et ali. Cenários de Gestão de Escolas Municipais no Brasil. Textos FCC, São Paulo: Fundação Carlos Chagas, v.54, 2018. http://publicacoes.fcc.org. br/ojs/index.php/textosfcc/issue/view/350. Acesso em 12/08/2019.

MARTINS, A. M.; REAL, G. C.; SOUSA, S. Z.; ROSA, S. S. Organização e funcionamento de escolas públicas municipais na percepção de diretores de escolas municipais. Relatório Final. Fundação Carlos Chagas, São Paulo, 2019 .

MELO, A. S. E. de; MAIA FILHO, O. N.; CHAVES, H.V. Conceitos básicos em intervenção grupal. Encontro: Revista de Psicologia, v. 17, n. 26, 2014, p. 4763.

Pesquisa-ação: gênese, aplicação e finalidade. Fractal: Revista de Psicologia, São Paulo, v. 28, n. 1, jan. -abr., 2016, p. 153-159, 2016.

PERRENOUD. P. Sucesso, na escola: só o currículo, nada mais que o currículo! Cadernos de Pesquisa, n. 119, julho/ 2003, p. 9-27.

REAL, G. C. M; SANTOS JUNIOR, J. S.; SOUSA, S. Z.; MARTINS, A. M.; BRAVO, M. H. Abandono, reprovação, reforço escolar: respostas de diretores ao questionário contextual da Prova Brasil. Revista Brasileira de Política e Administração da Educação, v. 35, n. 1, p. 249 - 268, jan. /abr. 2019 249-268.

ROCHEX, J.-Y. As três idades das políticas de educação prioritária: uma convergência europeia? Educação e Pesquisa, São Paulo, v.37 n.4, dec. 2011, p. $871-881$. 
ROSA, S. S.; CAMPOS, G. N.; PADOVAN, M. I.; UMEMURA, V. M. V. Gestão pedagógica e qualidade social da educação: contribuições da pesquisa colaborativa em escolas de São Caetano do Sul. Revista e-Curriculum, São Paulo, v.16, n.4, p.1457-1484, out. /dez, 2018.

\section{SÃo CAETANO DO SUl. Regimento Escolar Municipal da Rede Pública Municipal de Ensino de São Caetano do Sul. 2014. (mimeo)}

SÃO CAETANO DO SUL. Lei $\mathbf{n}^{\mathbf{0}} \mathbf{5 . 3 1 6}$, de 18 de junho de 2015. Aprova o Plano Municipal de Educação do Município de São Caetano. Departamento de Administração e Recursos Humanos. São Caetano, 18 jun. 2015.

SÃO CAETANO DO SUL. Lei $\mathbf{N}^{\mathbf{0}} \mathbf{5 . 5 5 6}$, de 20 de setembro de 2017. Dispõe sobre a criação do Sistema Municipal de Ensino de São Caetano do Sul e dá outras providências. Departamento de Administração e Recursos Humanos. São Caetano, 20 set. 2017.

SÃO CAETANO DO SUL. Lei Municipal n. 5.139/13. Dispõe sobre a obrigatoriedade da matrícula de irmãos no mesmo estabelecimento de ensino quando este oferecer turmas no mesmo nível educacional.

SÃO CAETANO DO SUL. Diário Oficial Eletrônico de São Caetano do Sul, Ano I. Edição n. 108, 26/09/2017a Disponível em: http://inscricoes. saocaetanodosul.sp.gov.br/processos/infantil/upload/edital_2018.pdf. Acesso em: 12 set. 2019.

SÃO CAETANO DO SUL. Secretaria Municipal de Educação. Edital Processo Seletivo Ensino Médio 2018. São Caetano do Sul, 06/11/2017b. Disponível em: http://inscricoes.saocaetanodosul.sp.gov.br/processos/medio/ Acesso em: 12 set. 2019.

SECRETARIA DE ESTADO DE EDUCAÇÃO DE SÃO PAULO. Resolução SE $\mathbf{n}^{\mathbf{0}} \mathbf{4 5}$, de 18 de julho de 2018. Estabelece critérios e procedimentos para a implementação do Programa de Matrícula Antecipada/Chamada Escolar, com vistas ao pleno atendimento à demanda do Ensino Fundamental, na rede pública de ensino do Estado de São Paulo. 
SORDI, M. R.; OLIVEIRA, S. B. DE; SILVA, M. M. DA; BERTAGNA, R. H.; DALBEN, A. Indicadores de qualidade social da escola pública: avançando no campo avaliativo. Estudos em Avaliação Educacional, São Paulo, v. 27, n. 66, p. 716-753, set./dez. 2016.

SOUSA, S. Z.; MARTINS, A. M. Composição e organização da clientela escolar em escolas municipais brasileiras: o que dizem os diretores. Educar em Revista, Curitiba, v. 34, 2018, p. 175-190.

STAKE, R. Pesquisa qualitativa: estudando como as coisas funcionam. Porto Alegre: Penso, 2011.

TORRECILLA, F. J. M. Um Panorama da pesquisa ibero-americana sobre a eficácia escolar. In: BROOKE, N.; SOARES, J. F. (orgs.). Pesquisa em eficácia escolar - origem e trajetórias. Belo Horizonte. Editora da UFMG, 2008, p. 466481.

\section{Angela Maria Martins}

É pesquisadora da Fundação Carlos Chagas, professora titular do Programa de Pós-Graduação em Educação e do Mestrado Formação de Gestores Educacionais da Universidade Cidade de São Paulo. E-mail: ange.martins@uol.com.br

\section{Sanny da Silva Rosa}

É professora da Universidade Municipal de São Caetano do Sul. E-mail: ssdarosa@uol.com.br

\section{Sandra Zakia Sousa}

É professora da Faculdade de Educação da Universidade de São Paulo, consultora da Fundação Carlos Chagas. E-mail: sanzakia@usp.br 